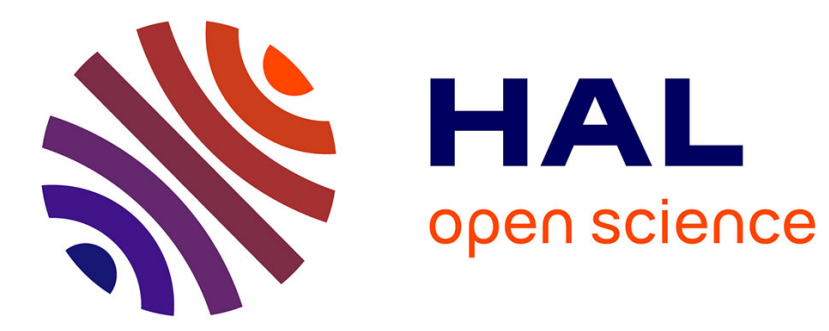

\title{
Urban research and complexity
}

Denise Pumain

\section{To cite this version:}

Denise Pumain. Urban research and complexity. Cesare Bertuglia, G. Bianchi, e A. Mela. The city and its sciences, Physica Verlag, pp.323-362, 1998, 978-3-642-95929-5. halshs-01625487

\section{HAL Id: halshs-01625487 https://shs.hal.science/halshs-01625487}

Submitted on 27 Oct 2017

HAL is a multi-disciplinary open access archive for the deposit and dissemination of scientific research documents, whether they are published or not. The documents may come from teaching and research institutions in France or abroad, or from public or private research centers.
L'archive ouverte pluridisciplinaire HAL, est destinée au dépôt et à la diffusion de documents scientifiques de niveau recherche, publiés ou non, émanant des établissements d'enseignement et de recherche français ou étrangers, des laboratoires publics ou privés. 


\title{
URBAN RESEARCH AND COMPLEXITY
}

\author{
Denise Pumain
}

\section{Introduction}

During the last two decades, a number of interesting innovations have appeared in the field of urban research. New paradigms such as the dynamics of open systems, self-organisation, synergetics, chaos and evolution theory, have been recognised as conveying fruitful analogies for urban theory. New types of modelling, such as sets of non-linear differential equations for spatial systems, cellular automata, multi-agents models, fractal growth, neural networks and evolutionary models have been investigated. By reviewing the orientations of contemporary urban research, it is possible to recognize among these new urban models, several types of strategies which are used for dealing with the complexity of urban systems.

It is not our purpose to provide an impossibly exhaustive review of new trends in urban research. Several specialised reviews have already been published about operational intra-urban models (Wegener, 1994), computer-oriented urban modeling (Batty, 1992), or about models of systems of cities (Mulligan, 1984, Pumain, 1991), and urban models in general (Bertuglia, La Bella, 1991). We would therefore like to focus on how these new conceptual or operational tools may be useful for solving some of the problems linked with urban complexity.

Before analysing some of these research strategies, it is necessary to recall which are the main sources of difficulty for urban research to attain its object of study, to define it and to build consistent theories about it. The main theoretical issues in urban research will then be examined through the various methodologies which have been proposed recently in order to solve the oxymoronic task of making complex urban systems simple.

One may also wonder how much the new ideas have added to urban theory and general knowledge about cities. It can be observed, on the one hand, that a large number of the models built have never been applied, nor have they been rigorously compared with other models. On the other hand, several new results and interesting pieces of thinking have been brought about by much more classical types of approach, without any connections with complexity studies. Such closures and delays in communication are frequently observed in science but, if prolongated, they may be detrimental to urban research and planning. 


\section{Various sources of complexity in urban systems}

Since urban systems are considered as objects of significance for research, a large part of the theoretical thinking has been devoted to the scientific appraisal of the urban realm.

All authors recognize that cities are objects too complex and too diverse to be approached as a unified conception. The difficulty about building one concept of a city has its roots in the uncertain origins of urbanism, in the manifold aspects of urban life and is reflected in the variety of the measures which are used for defining the urban areas.

\subsection{Definitional complexity}

Historians agree upon the universality of the urbanisation process : cities appeared independently on various parts of the earth surface at about the same time. However, there is a controversy about the nature and significance of urbanisation. A few authors insist on the economic dimension : two or three thousand years after the invention of agriculture, towns began to emerge in order to commercialise the agricultural surplus, by trading manufactured goods : "not only has agriculture been an absolute prerequisite to the emergence of true urban systems, but there exists also an inverse relation : agriculture lead almost ineluctably to the town" (Bairoch, 1985 , p. 631). Other authors maintain that the main function of cities belongs to the symbolic order, it is part of the carrying out of power : "the city is characterised neither by its number of inhabitants nor by their activities, but by particular features of legal status, of sociability and culture... those features are consequences of the main role of the urban organism. That role is not economical, it is political" (Duby, 1980, p. 13). For others, it is the collective relationship to the feeling of sacred (Racine, 1993) which has created the cities : "in any of the seven regions of the first urban generation, if one traces the characteristics of the emerging urban form, one arrives not at a settlement which would be dominated by commercial trade, or which would be centered on a citadel, an archetypal fortress, but more likely at a ceremonial complex" (Weatley, 1971).

This diversity in the theoretical interpretations of the origins of towns and cities is further increased by the variety of their theoretical definitions and according to the point of view which is chosen, whether anthropological, cultural, economical, geographical, political, religious or social...

According to a demographic definition, a city is a permanent grouping of an amount of resident population on a small surface. Size and density of the aggregated settlement are linked within a morphological definition, which also recognizes the temporal persistency and spatial continuity of building, and of the urbanistic rules in their organisation. Such a conception implies that the city cannot produce, on the limited surface that it occupies, the totality of food that it 
needs. Its survival depends then on trading between the manufactured goods and the services that it produces and the agricultural goods which are necessary to its population. A functional definition, or a social and economic one, results from this situation: the city groups nonagricultural activities and innovates by developing a more or less complex social division of labour. This diversified economic base forms the carrying capacity of the town.

The commercial trade between towns and the countryside is always unequal, as manufactured goods are over-evaluated when compared to food stuffs (Aydalot, 1985, Camagni, 1992). The economic advantage so given to the town is unseparable from its legal status, as a place of power. Even if this power has a religious or political origin, it is linked with an economic and territorial privilege and grants the town a dominance over the neighbouring localities (Racine, 1993).

This large variety of definitions is a first aspect of the complexity which characterize town and cities as objects of scientific research. In order to get a full understanding of such a manifold object, it is indeed impossible to reduce it to a single of its multiple dimensions, even in the realm of a well-established discipline : a theoretical economic approach to the city cannot ignore its political and symbolic aspects, a pure social theory of the city would miss out the spatial and morphological features which are essential to its characterisation. The study of cities cannot therefore be confined to a specific field of investigation, as it is sometimes possible and fruitful to do for other objects of social sciences. On the contrary, a relevant insight in urban dynamics can be obtained only by cross-fertilizing the urban disciplines: the explanation of economic success is to be searched in social and symbolic valuation processes, the types of social interaction cannot be understood without knowing their material conditions of existence in urbanism, and so on. As a consequence, the theoretical concepts elaborated within the framework of disciplinary research lose their explanatory power when applied to cities, as they are often insufficient, unable to deal with urban objects.

\subsection{Spatial complexity}

It has long been noticed that towns and cities have developed links with their surrounding environment : a settlement specialised in non agricultural activities carries out central functions for its complementary region (Reynaud, 1841, Christaller, 1933). Contrary to villages (or mining settlements) which exploit resources at their site, or in their close neighbourhood, towns and cities make a life of the wealth created by their situation. They valorize their position in trade networks, whose spatial range depends upon the size and specialisation of the city (Reymond, 1981a and b). For this reason, a city cannot be conceived of as an isolated entity, it always belongs to a network 
of cities, it is "a system within a systems of cities" (Berry, 1964). Systems of cities have their own regular properties which are not only the sum of the individual cities which compose them and they constitute a meaningful level for the analysis of urbanisation (Pred, 1977 ; Pumain, 1992).

The city as a scientific object of study should thus be conceived at its various levels of spatial organisation : the three levels of the individual actors, the city itself and the system of cities are always to be considered at least, whereas some intermediary levels as the neighbourhoods inside cities or some regional subset of cities may also sometimes be of interest.

However clear the identification of those levels of organisation from a conceptual point of view, it is often difficult to recognize them in reality. The neighbourhoods may have clear-cut edges but most of the time several different partitions of an urban space may be considered as relevant. The limits of the city itself have become fuzzy, due to the generalisation of suburbanization and of long distance commuting which has broken the spatial continuity of daily urban systems. It is also sometimes difficult to separate clearly a city and a network of cities, as in the case of large conurbations or the very densely connected regions like Randstad Holland, the Ruhr area, the rivieras or the Megalopolises. Systems of cities are also difficult to isolate as scientific objects of study. They are generally defined within the limits of a single country, since international borders greatly reduce the intensity of spatial interactions. However, it is obvious that interurban interactions are not negligible despite international borders. Moreover, the degree of openness of the system of cities varies according to the situation of each city within the urban system. The largest cities, or the ones which are specialised in international activities, are more open than the others to external interactions. It is therefore very difficult in practice to define precisely what are the effective limits of a system of cities.

Because of their obvious structuring in various organisational levels, urban systems belong to the category of complex systems. However, when compared to physical or biological systems, the handling of that complexity is made more difficult by the fact that the separation between the levels is not always easy to determine in practice.

\subsection{Temporal variations}

Another source of complexity makes the description and modelling of urban systems difficult: This is the multiplicity of time scales which are operating at the same time in the same city. For instance, one only has to consider how the timing of daily life adjusts (for instance by commuting) to the more stable pattern created by the location of jobs and housing facilities in the city. The life-time of the buildings is generally longer than the duration of stay of their users or 
inhabitants, or even of one generation of people (Whitehand, 1977). This lead to the well-known pattern of moves from central locations to the periphery and back to the centre, which are linked with the successive stages of the life cycle of individuals. But other time-scales, which may have a decisive and sometimes catastrophic effect on the life of its inhabitants, intervene in the life of a city: The duration of a cycle of economic specialisation (adoption of a large set of innovations) may be from a few decades to one century or more, inducing alternate periods of rapid growth, stability and slow decay. Even if cities succeed in adapting to several successive innovation waves, the speed of change of the economic and social functions is generally quicker than the speed of transformation in the town plan and infrastructure. All these differences in the time scales of the component of an urban entity cause severe disfunctioning in the everyday life of cities, and also make the description of the dynamics of the urban systems very difficult. Not only do the relevant steps of time have to be identified, but also mechanisms articulating various temporalities have to be considered.

Without being too deterministic, or playing with ideas about finalism, we could suggest that the articulation of such different temporalities, which is part of urban complexity, is also a condition which explains the survival and the persistency of cities over very long periods of time. The same structures can respond to very different social needs and economic activities, and this adaptability and flexibility ensures the sustainability of the whole urban system.

Momentary disadaptation of form to function, congestion phenomena, time lags in adjustments to change, mismatch in facilities and infrastructure, discrepancies between real needs and the objectives of policies may result from the inequalities in the intrinsic duration of the lifecycle of each of the components in an urban system. The analytical handling of such a large variety of time-scales is very difficult and is one main source of the problems faced by urban theory and modelling when they try to conceptualise the urban change.

This challenge is reinforced by another consequence of the temporal variability of urban systems, which is their historical, or rather, evolutionary character.

\subsection{Urban systems are evolutionary}

Urban systems are also complex because they cannot be wrapped up in a stable taxonomic description. The social and economic content of cities and its significance is changing over time. Different "generations" of towns and cities have to be characterized differently, according to their morphological aspect as well as to their urban functions. These changes lead to the disappearance of some cities (abandoned citadels, or the "ghost towns" of the gold rush), but 
most of the time the transformations and adaptations occur within a permanent urban entity. Cities are very often considered as the main vectors of social transformation and technological innovation. This adaptation process induces more or less pronounced specializations of towns and cities into functional types. Several successive successful adaptations or failures to transform determine strong inequalities in city size. Meanwhile, the significance of size thresholds is also evolving over time. The qualitative content referred to by concepts such as a 'small' town, a 'large' city, an 'industrial' or an 'administrative' one, has to be constantly revised. As it concerns innovation and creation, this particular process of urban change is very difficult to include in models which attempt to make predictions.

This process is also a source of complexity in the sense that the integration of social interactions in a temporal accumulation produces networks of relations which have a long existence and persist beyond the migrations of people and even the passage of generations. Towns and cities become indivisible objects and cannot be analysed as the juxtaposition of their different parts. It is highly significant for instance that a conurbation resulting of the merging of two or three independently grown cities will not reach the same functional level as a unique monocentric city of the same size before a very long time (many decades or centuries).

At another scale of study, systems of cities also have an evolutionary character. Archaeology supports the idea that since the very beginning, towns have not appeared in an isolated way, but in numbers and with linkages making them function in networks (Fletscher, 1986 ; Bairoch, 1985). Two main theories of the genesis of city systems, bottom-up and topdown, are probably complementary. To the idea that towns and cities derive from the surrounding rural region which feeds them, corresponds a theoretical approach of systems of cities as covering and controlling a territory for ensuring its defense and for meeting the other needs of its inhabitants (Botero, 1588, Vauban, 1707 ; Le Maitre, 1682, Reynaud 1841 ; Christaller, 1933). To the observation that cities are from the very beginning organised in networks is related an approach viewing cities as nodes within various systems of relations and analysing interdependencies without considering too much their immediate environment (Reclus, 1895, Bird, 1977, Batten, 1992, Dematteis, 1985 and 1990, Camagni, 1990).

In both cases, an intrinsic property of city systems is that their size is linked with the productivity increases of agricultural and industrial or tertiary activities ensuring their subsistence, as well as with demographic growth.The space-time contraction process generated by the increasing velocity of communications is another major historical trend in the evolution of geographical space, which strongly constrains the development of urban systems (Chevalier, 1832, Reclus, 1895, Juillard, 1972). The spacing and hierarchical structure of systems of cities is highly 
connected to the evolution of the relative speeds of intra-urban and inter-urban communication (Pumain, 1993). Therefore, systems of cities can hardly be modelled as systems in equilibrium, as intended for instance by central place theory, since any explanatory theory has to take into account that they are produced by the historical process of the development of settlement systems, i.e. the urban transition. This is another important feature of urban complexity.

Until now we have used the concept of complexity without defining it. This concept as become very fashionable, because it raises echos in various field of knowledge, especially in biological and social sciences. However, contrary to the integrative views of some specialists in "complexology", as developped for instance at the Santa Fe Institute by S. Kauffman (1993), we are skeptical about the possibility of finding universal "laws of complexity" which would be applicable to all "complex" systems. That is why we started by specifying how the concept of complexity could be understood when dealing with urban theory. Those specifications help to precise which demands can be addressed to more general theories of systems dynamics and which useful notions or models could be extracted from other fields of research. One strategy for dealing with all four main aspects of complexity for urban systems has actually been to borrow ideas and techniques from theories developed in the field of mathematics, physical or biological sciences.

\section{New paradigms for the modeling of complexity}

One component of urban complexity is the fact that the same mechanisms, or rules, or planning principles, may lead to different structures, according to the situation of the city under study and the moment of its evolution. The same action (external perturbation or internal change) may have no effect if the city is on a stable dynamic trajectory, but it can deeply alter the structure if it intervenes at a moment of instability, when bifurcations are possible. The ability of sets of mathematical non-linear equations to reproduce such a variety of qualitative behaviour has been used in several types of models of urban structures. Most of those models have been transferred from physics and rely upon analogies between urban systems and self-organising systems.

\subsection{Principles of self-organisation}

Dynamic models of urban structures are designed in order to understand better and anticipate the evolution of such socio-spatial systems. New dynamic models mainly draw upon analogies from physics, for instance chemical kinetics (Allen, 1978) or laser theory (Haag and Weidlich, 1984). The systems concerned are described on at least two levels : system-wide (macroscopic variables) and elementary (microscopic level). There is a very large number of 
elements in the system. Sometimes a third level of description is added, with subsystems comprising unfixed numbers of elements. Differential equations describe the variation of a macroscopic variable over time. They are obtained from definitions of interactions at the microscopic level, between the elements of the system. The passage from the microscopic level to the macroscopic description of the system is the most arduous problem in such model building. It may lead to stochastic formulations when interactions between the elements do not have a deterministic form but their results are known only as probability distributions.

According to physical theories such as the "dissipative" structures theory or "synergetic theory" (Haken, 1977) phenomena of self-organization and of bifurcation may occur in open systems when they are maintained under an influx of energy. These systems may organize themselves into structures which are created or destroyed during the evolution of the system. This evolution is both deterministic, according to a trajectory which can be predicted using the equations of a model describing interdependencies between variables; and random, or undetermined, during periods of instability when a change in structure (or a phase transition) can occur. The equations of the model may therefore admit several solutions or multiple dynamic equilibria, several possible trajectories corresponding to qualitatively different structures, between which the system may be driven towards one branch or another, towards a given form of organization, by the amplification of a small fluctuation (after Prigogine and Stengers, 1979 and Allen and Sanglier, 1981).

Many sources of instability intervene in the evolution of such open systems when they are situated far from equilibrium. On the one hand they continually undergo internal fluctuations, variations in the level of their characteristic variables (which may result from changes in the microstates of the elements of the system) ; on the other hand, they are always subject to external perturbations stemming from their environment. An open system is thus continually adjusting the level of its variables or the size of its subsystems. It maintains a relative structural persistence only when this structure constitutes, under the given conditions, a stable state for the system ; that is a state towards which the system returns after having distanced itself a little. The structure is then viewed as an attractor on the system's trajectory. The dynamical instability may induce a passage from one trajectory to another, from one structure to another structure, that is from a given qualitative behaviour of the system to another, through a bifurcation point.

This paradigm provides a new framework for urban theory and urban modeling. Accordind to M. Batty (1994), such a change in paradigm can be related to a change in the city itself: "for a hundred years or more, urban theorists have treated cities as though equilibrium were their natural condition. However, as current events increasingly demonstrate, this is less and less 
true. As the local and the global intersect in unanticipated ways, and as the role of historical happenstance is seen to be more influential than ever, as the evolution of ever more complexity seems to be the norm, we sorely need new theories of how cities form, how they evolve, and how we might control or at least influence their development" (p.14).

\subsection{Transfering the theory from physics to urban research}

To what extent does it appear useful to develop an analogy between such physical systems and urban systems?

When formalizing an urban entity in this framework as a dynamic spatial system, one has to define it as a set of elements, which are either located elements or geographical zones. Location (at least relative location) is a basic property of the elements of the system ; the interactions between those elements are at least partly spatial interactions, which are linked to expressions of the absolute (site) or relative (situation) location of the elements. The state of the system is defined as the configuration of its characteristic variables. A geographical structure is then given by a particular relative size and evolution for the state variables and/or located subsystems which are used for the description of the urban system.

At the most disaggregated level, an urban system can be formalized as a set of localized and interacting actors (individuals or groups as persons, households, firms, associations...etc) who are using and continuously re-creating geographical differences and spatial configurations. These interactions are various in nature and form : competition for space, propensity to agglomerate, segregation tendencies, imitation... and so on. According to the case, they generate the homogeneity or the diversity of contents, the increase or the decrease in gradients, the concentration or the dispersal in distributions. One has to hypothesize that the dynamics of these interactions is creating the spatial structures, for which they are both an expression and their condition for existence.

Such a formalization has many appealing features :

- It allows stress to be placed upon the linkages between the individual behaviour of the actors and interactions defined at this microscopic level on the one hand, and the macroscopic descriptors of the system on the other. Much research has been conducted and empirical regularities have been established for each scale of study separately, though a clear connection between the two levels of observation is not always established. Here, self-organization phenomena, meso - or macro-scale structures, are described as consequences of an interaction game between individuals, each animated by their own objectives. These consequences are not 
always intuitive to the observer, they are often not concerted and most of the time are not perceived by the actors.

- This approach may also provide an interpretative framework for observed regularities in urban systems. Due to the instability of elements being considered, it is only because bifurcations occur in the evolution of dynamic systems, because their trajectories "jump" from one attractor to another, that identifiable and separable categories, or large-scale regularities, may be observed. Temporal series therefore appear as "possible" sequences of complex dynamic. Very often the problem for social sciences, where experimentation is impossible, consists of identifying the dynamics which produced a particular temporal series of observable structures i.e. a specific trajectory (Prigogine and Stengers, 1979).

- Another interesting feature of this approach is that the historical dimension of social systems is taken into account via the concept of irreversibility. On the one hand, the explanation of the state of a system at a given date integrates its previous trajectory (i.e. its history) and the contemporary structure includes the "memory" of previous bifurcations. On the other hand, the characteristic fluctuations of dynamic systems imply that it is impossible to prepare initial conditions which would lead to identical futures. The impossibility of exact prediction is then given as a theoretical "a priori". However, the analysis of the dynamic behaviour of the systems and of their sensitivity to changes in parameter values allows the exploration of a limited number of possible futures, according to the assumptions made about the evolution of the parameter (Allen and Sanglier, 1981).

These ideas may appear seductive. But it is not because of their novelty : all of them were originally expressed a considerable time ago. Rather it is because they allow the relaxation of some of the more oppressive restrictions imposed by the previous methods of model building and because new experimental tools related to these old ideas are therefore available. The new models can from now on be in agreement with these old ideas, reformulated as a "new" urban theory.

Since systems theory is applied to urban systems, a noticeable evolution can be observed in the scientific domains where analogies are drawn out. The first uses of a concept like entropy for instance was referring to statistical mechanics, and then to information theory. System dynamics had their first inspiration in hydraulics (Forrester, 1969). The dynamics of cities as open systems far from equilibrium was first conceived with reference to "dissipative structures" or "synergetics", conveying analogies with physical systems. Another way of thinking is more and more guiding the work of urban theoricians and modelers. They still use the mathematical tools which were first proposed by physicists (or mathematicians) for building and testing their models, 
but they refer themselves more often to theoretical analogies with living systems. A shift is made from the pure concept of "dynamics" to the concept of "evolution" (Allen, 1991, Rabino, 1993). Although urban systems can be described as largely self-organized open systems, whose structure and evolution depends upon internal fluctuations as well as external fluctuations, they also have a historical an evolutive behaviour, as well as an adaptive hierarchical structure and a power of creativity, which invites to develop more analogies with living systems.

Besides some tentative transfers of concepts from ecology (Dendrinos and Mullaly, 1985), which is by no means a new inspiration for urbanists since the famous Chicago school, or some interesting use of Atlan's work by urban modelers (Camagni et al. 1986, Diappi et al. 1994) there has been very little further serious research for introducing the concepts of evolution theory in urban theory, despite a more and more extensive use of the word itself. The rather bad reputation of social darwinism is perhaps too dissuasive. On the other hand, even if urban systems seem to have many features in common with living systems, they also have distinctive social properties, like the intentionality of their organizations as well as their short-term learning capacities, which may lead to search for other analogies. This has been made in direction of computational automata or artifical intelligence (Huberman, 1988). A few devices like cellular automata or neural networks are now explored for applications in urban modeling, which may be connected to evolutionnist theories and incorporate more classical dynamic tools. A new and more specific theory of urban evolution could emerge from these experiments, if they are well related to empirical research.

A short review of some applications of dynamic modeling to intra- and inter-urban structures will demonstrate a large diversity of inspiration of urban modelers. But probably not all experiments can become part of urban theory or operational tools, even if they all were challenged by the idea of reducing or explaining better the complexity of urban systems.

\section{Quantitative models of qualitative structures}

When using non-linear equations and/or interdependencies between variables, even very simple mathematical models can produce very complicated dynamics (May 1976).

The property of differential non-linear equations in generating a complex behaviour for the state variables of a system has been used in several ways. When rather realistic projections are needed, one safe approach is the search for analytical solutions, which lead to simpler formulations of urban models, whereas another trend is to develop more realistic and complete representations 
of cities, but with an exploratory use of the models only. In both cases, the mathematical tools are used to provide a variety of possible qualitative structures from the same set of equations, i.e. the same kind of urban mechanisms, by changing only the value of some parameters. Applications are always made for aggregate variables, either at a city level or for a system of cities.

\subsection{Analytical models of urban growth}

The formulations which are used for these models are more or less directly drawn from findings in other fields: catastrophe theory in mathematics, Volterra-Lotka models of interacting species in biology, and master-equation techniques from physics. All these models are conceived for giving analytical solutions, with the implication that one knows how to identify the equilibrium states of the system, how many they are and whether they are stable or not. One is then able to situate the observed trajectory with respect to these equilibria and to make predictions about the stability of the structure according to hypothetical variations in the values of parameters.

\section{Catastrophe theory}

R. Thom's (1974) catastrophe theory provides very good analytical tools and theorems about the number and precise qualitative shape of the functions linking the state-variables to the elementary catastrophes. However, it allows too small a number of variables and parameters to describe the system (respectively a maximum of two and four), so that it cannot be of great help in most of urban problems. Lung (1985) underlines the difficulties in constructing models which satisfy the basic assumptions of the theory: how to define a potential function, how to incorporate competition for space, and how to find relevant state variables which may undergo sudden changes, yet produce another qualitative structure for smooth variations in the values of parameters.

Reviews of these applications are given by Wilson (1981) and Rosser (1991). Usually the spatial structure is summarized by a global measure of size, or density, or intensity of spatial interaction, whose variations are related to a few control parameters. For instance, Amson (1975) considers urban density as a state variable, which is dependent upon two parameters: it is proportional to rental and inversely proportional to "opulence", which is a measure of the benefit from urban interaction. He then shows that urban density follows variations according to the fold model if a saturation effect is introduced, with rental becoming a logistic function of density. If a minimal threshold of available space per person is added, the model for the variations of the density becomes a cusp. The condition for a smooth and continuous behaviour of the density is that one of the parameters, rental or opulence, will keep high values. 
Catastrophe theory is used by many authors to describe discontinuities in urban growth. For example, Mees (1975) gives an interpretation of the revival of cities in Europe between the 11 th and 13th centuries, following a long period of urban decline, as a discontinuity in the relationship between the urbanisation rate and the possibility of external trade. This discontinuity appears at a critical value in decreasing transportation prices. A more comprehensive model involving a butterfly catastrophe takes as a state variable the population working in manufacturing in towns, which is a function of four control variables: density of regional population, average productivity, urban-rural productivity differential and difficulty of transport. Papageorgiou (1980) tries to explain the cases of sudden urban growth observed in the 19th and 20th centuries by existence of scale economies in the utility function of cities for individuals. Technological changes, even when utility increases in a continuous manner, may at a given level introduce a discontinuity in the urbanization rate, which then jumps from one equilibrium point to another, in accordance to a fold catastrophe. A simpler test has been provided more recently by Casetti (1991) and describes a transition between two equilibrium states in the urbanisation rates of the world between the XVII and the XXth centuries as a cusp catastrophe .

A third approach consists of explaining the existence of thresholds and hierarchical levels in urban systems by the jumps and hysteresis phenomena of catastrophe theory. In this fashion Casti and Swain (1975) suggest that the functional level of a central place may be seen as a cusp function of two control variables: population and per capita income, whereas Wilson (1981) relates the size of various urban facilities and urban centers to the benefits of facility size and to the disbenefits of travel. If the first control variable is a logistic function of size, and the second a linear one, the size may vary with the slope of this last function according to a kind of fold catastrophe.

The most interesting feature of this family of models seems then that they provide good theoretical insights into the discontinuous behaviour of some aggregate variables. But they are still of little help in the modelling of spatial structure or spatial interactions in urban systems.

\section{Volterra-Lotka's model}

This formulation depicts the evolution of the number of individuals belonging to two interacting biological species. Each species is also characterized by a birth-death process of the logistic type. Translations of this formulation to geographical analysis have been attempted for instance by Dendrinos (1980 and 1984) and Dendrinos and Mullaly (1981 and 1985). In their urban model the variables used in place of species are the city's population and its mean per capita income. The model then simulates the evolution of the share of an SMSA's population in the total 
national population $x$ and of its relative level of per capita income $y$. So spatial interaction is not easily included in that kind of model structure. Equations of the model are of the following form:

$$
\begin{aligned}
& \mathrm{dx} / \mathrm{dt}=\alpha(\mathrm{x}(\mathrm{y}-1)-\beta \mathrm{x} \\
& \mathrm{dy} / \mathrm{dt}=\mathrm{y} \gamma(\mathrm{X}-\mathrm{x})
\end{aligned}
$$

where $\mathrm{X}$ is a carrying capacity of the SMSA, $\alpha$ and $\gamma$ are speeds of adjustment and $\beta$ a coefficient of "urban friction". This model was chosen because it allows replication of one of the most frequent behaviours observed among the 90 SMSAs of the United States between 1940 and 1977. Such behaviour is the sink-spiral type, with oscillations around successive equilibria. However, the scarcity of available temporal data does not allow a strong empirical support to this model.

Volterra-Lotka formalisations are appealing because of the diversity of dynamics that they can generate from relatively simple mathematical equations, and because the trajectories and the stable states can be analytically computed. They have been used for instance for reproducing cyclical behaviour in the relative development of an urban center and its periphery (Orishimo, 1987, Zhang, 1990), according to the hypothetical model proposed by Klaassen (pre-urbanisation, urbanisation, de-urbanisation and re-urbanisation). Volterra-Lotka's equations also are used in various models of competition for city space between two types of land use or between two categories of urban citizens. There is still much work to be done in testing such models, selecting the more often observed cases among the six theoretical equilibrium states according to an ecological analogy (symbiosis, competition, commensality, amensality and isolation). For several of the models which have been proposed, the exact interpretation and measurement of the model parameters is not entirely clear.

Spatial interaction also is not easily included in this kind of model structure. In most cases, it appears only in a weak and implicit manner, since the size of one element in the system is expressed by a relative measure, as a share of the total sizes of the elements of the system.

\section{Master-Equation Approach}

The master-equation method relies upon theoretical principles used in the field of synergetics. It is potentially of great interest to urban research, because it links explicitly the state transition probabilities of individuals at a micro-level, and the evolution of some variables 
describing a macroscopic structure. The master equation gives the variation in time of the probability of the possible configurations in the space of the state-variables. This probability of transition from one configuration to another depends on the assumptions made about the number and nature of parameters affecting the individual transition probabilities. This stochastic formulation is then used to derive a deterministic equation for the evolution of the mean values which, in turn, allows the estimation of the parameters.

This procedure has been used for deriving a two-population-two zone model of the Volterra-Lotka type (Haag, 1984). The migration rate of each population group from one zone to another depends on its preference for a given part of the city, its propensity to cluster ("internal sympathy"), and to join members of the other group ("external sympathy"), and a general mobility level (flexibility). The authors explore analytically all possible types of spatial configuration and levels of urban segregation according to the sets of values taken by these four parameters. In this simple version, such a model is a good pedagogical presentation of an elementary spatial dynamics.

The master equation approach has also been used for reformulating an intra-urban model of residential rent and density interactions (Haag and Dendrinos, 1983) and has been applied to twelve SMSA of the United States (Dendrinos and Haag, 1984). The SMSA are divided into two parts: the city center, and the suburbs. Utility functions depending on rent and density levels through land availability are used to describe the individual behaviour of typical land-buyers (who move) and sellers (who transfer rental value from one zone to another). Aggregation of these individual behaviours produces a stochastic master equation, whose deterministic mean value describes the evolution of the population share and of the relative rent price in the central part of the urban unit. From simulations with empirical data, the authors predict a probable reversal in the sururbanization trend for the 1990's, if the parameter values which stand for the common general conditions of the SMSA's environment do not change over time.

A model of migration for a whole set of regions has been constructed under the same approach (Haag and Weidlich, 1984). Individual transition probabilities from one spatial subdivision to another are defined as functions of the difference in the attractivity of regions. They are aggregated to define an equation of movement of the probability of states of the system (e.g.: all possible configurations of population repartition among regions), whose mean values equation is used for the estimation of parameters. The dynamics of the spatial system is then related to trend parameters whose values may be compared from one system to another, or over time (global mobility rate, "co-operation", i.e. an agglomeration effect, and a saturation effect), and to a set of preferences for each region. The socio-economic variables which could explain these preferences 
are not included in the dynamic model. However, when fitted by a regression model upon a temporal series of preferences as established from the model (after for instance annual migration tables), they allow a prediction of future migration patterns and of the further evolution of the spatial configuration of population. The actual spatial configuration of population also may be compared to the stable state which would emerge from the observed pattern of migration flows if prolongated. The deviation between the two gives an idea of the strength of the ongoing structural reorganisation in the system.

L. Sanders (1992) applied this model to a large set of French cities observed between 1954 and 1982. She relates the shift of the migratory preferences, from the north-eastern cities to the southern ones, to the emergence of business services as a major source of differentiation in the contemporary dynamics of the system of cities. She also provides various scenarios of possible further evolution, which can be obtained from different hypothesis about the future migratory trends (Haag et al., 1992).

Because of their computational ease, we classify models using a master equation approach with the models allowing for analytical solutions of dynamical structures, even if that solution in some cases may only be attained by iteration. These models also belong to the analytical category in the sense that they give very detailed and precise information about the dynamics of a very small number of state variables (one or two). Like Catastrophe theory or Volterra-Lotka's applications, they mostly deal with state variables at the aggregate level of an entire city or of a system of cities. This could seem a misunderstanding of the method, as master equation theoretically provides a clear relationship between the spatial behaviour of individuals and the global dynamics of the population configuration as measured by aggregated variables. However, despite this theoretical possibility, the handling of the master equation itself would be too difficult in practice and one has to make simplifying assumptions to define a mean value equation (Haag, 1984). What is defined in the migration model as a "utility" at the individual level is actually an aggregated measure of the "attractivity" of each zone (Sanders, Pumain, 1992). In reality, the migration model functions and give results for the aggregated level of the state variables of the system.

\subsection{Global models of urban structures}

A second group of modeling approaches uses non-linear differential equations in order to simulate the changes in the spatial structure of an urban area without paying so much attention to 
the existence and computation of precise analytical solutions for stable equilibria. They emphasize the production of a variety of possible spatial structures which are studied, in an exploratory way, with the help of simulations. The equations of the systems are more complex since a large number of state variables and interactions between them are used for the description of the system. The models are therefore more realistic representations of a city.

\section{Dynamics of spatial urban structures}

By using continuous differential equations instead of difference equations, and by drawing their analogies from models in chemics or physics instead of hydraulics, these models are more flexible than the previous urban dynamic model of Forrester (1969). They also represent progress by allowing a description of the spatial structure of cities in several zones, while the attempts for spatialising Forrester's model turned out to be very cumbersome (Fournier, 1990). The models exploring how a variety of urban forms can be generated from deterministic non-linear equations are mainly models of intra-urban structures. They describe the evolution of the location of populations and economic activities inside an urban area, usually by counting the number of jobs and residents of various types for each neighbourhood and computing interaction flows between them. These models can be considered dynamic extensions of the Lowry model (1964), as they integrate the same general principles well-established by urban empirical research (economic base theory, agglomeration economies, logistic growth and spatial interaction functions), within a framework of an atomistic and market-oriented urban economy. These traditional elements of urban theory were for the first time brought together in a single dynamic context by Harris and Wilson (1978) and P. Allen's intra-urban models (Allen, 1978, Allen et al., 1981).

Another very interesting improvement is that these models take into account the effect of external relationships on a city's development, whereas Forrester located the main source of a city's dynamics within the city itself, in its internal structure. For most models of the Leeds school (Wilson, 1981), as well as for P. Allen's intra-urban model, there is an external demand which plays a major role as a driving force in making a city grow or decline. Some authors have argued that these urban models were only kinetic and not really dynamic since they did not integrate endogeneously the causes of the evolution of the urban system. It seems that this interpretation is too severe and that the hypothesis of an external driving force is on the contrary interesting from a theoretical perspective, since it is an acknowledgment of the multi-level character of urban systems and of their dynamics. The observations about the real autonomy of a city as a "system", in Berry's sense (1964) actually show that inside a city, the "settlement system", including not only the housing but all the associated infrastructure and services, has some degree of autonomy. Its evolution depends mainly on local decisions, whereas the city as an economic system made up of 
firms has no real local autonomy, as its evolution is strongly determined by external linkages and decisions located outside the city, and sometimes very far away, in other parts of the world (Reymond, 1981a).

\section{Identifying bifurcations}

Wilson's and Allen's models of urban spatial structures have indeed thrown light on urban spatial dynamics by establishing explicit connexions between some critical parameters values and the shape of spatial urban patterns. The models developed at Leeds under A. Wilson's direction are more linked to the above mentioned analytical approach since they can be subdivided into submodels generating travel-to-work or residential shopping patterns of flows, allowing for some analytical descriptions of the morphogenesis of the location pattern of places of residences or of shopping centres for instance. Bifurcations and equilibrium points may be studied analytically for variations of one parameter, the other being held constant. The determining effect of the sensitivity of people to travel costs in shaping the pattern of residences and the strong impact of a parameter describing the sensitivity of consumers to scale economies in generating a concentrated or dispersed pattern of shopping centers illustrate the concept of bifurcation. Above a critical value of the parameter, the city evolves towards a concentrated pattern, whereas below this value, the pattern will become fully dispersed. For more complex formulations of the models, linking the supply-side and the demand-side of the urban dynamics, and disaggregating the variables into various income groups, types of housing or kinds of economic activities, the global dynamics of the system can be studied, by means of simulations (Beaumont et al., 1981a and b, Clarke, Wilson, $1983 \mathrm{a}$ and $\mathrm{b})$.

In P. Allen's work, the whole set of interactions is integrated into the equations of a single model, so that analytical solutions for some sub-systems cannot be computed. Spatial interactions are modeled mainly by the means of attractivity functions which characterize the advantages of one location in comparison with all other possible locations for each state variable in the system. The mathematical expression of such an attractivity function is very complex and the dynamic behaviour of the variables can be studied only by means of simulations. However, it is clear from the applications of the model to real cities (Allen, Engelen, Sanglier, 1984, Pumain et al., 1989) that bifurcations may occur and totally transform the spatial structure of the city, even for a very small variation of some parameter (for instance the one measuring scale economies or the propensity of economic activities to agglomerate).

So in both cases, the same mechanisms of spatial and economic interactions occuring within a city may give rise to a variety of spatial structures. Interpreting the structure of a given 
city according to this theoretical framework allows us to conceive that particular shape as one of the possible results of a more general urban dynamics, which could have generated many other shapes as well. Because of the irreversibility of the evolution, the successive bifurcations between possible trajectories determine the unicity of the actual pattern of each particular city. Despite this unicity, a general theory of the rules governing the functioning and evolution of urban structures seems no longer an unattainable aim for urban research.

In practice, the identification of when the bifurcations actually occur and what they are remains nevertheless a difficulty of this approach. Even though they may be well defined in theory, they are not easy to recognize from the observations about one real city or when calibrating a model, because changes in social systems occur most of the time with slow transitions, and because the limits between what may be considered as two different structures are very fuzzy. According to the length of the observed time period, a change in a trajectory may be interpreted as a shift towards a distinct trajectory through a bifurcation point. However, a longer period of observation may reveal that this apparent move was only a momentary fluctuation in a general evolution which actually maintained the same overall direction. For the same reasons, it is also very difficult to distinguish between two possible interpretations of an urban structural change: whether it is a jump to another trajectory remaining within the same type of dynamics, or a change which implies another definition of the urban structure and hence a change in the dynamic model itself. Usually, the slowness of transitions and the inertia of the structures are not well reproduced by dynamic models. The applications of the models have shown that they usually produce bifurcations more easily and more frequently than can be observed in reality (Wegener, 1983, Sanders, 1992).

\section{The question of temporal scales}

The bifurcations which can be observed in the spatial structure of a city are, in reality, very rare events, linked with nonpredictable external perturbations (such as sismicity or war), or happen only if very long time periods are considered. If more numerous bifurcations occur at small scales, for instance in the everyday life of individuals by taking small decisions, their effects on the urban environment are in most cases negligible. Bifurcations can be noticed only on longer time scales at higher spatial levels, for instance in the reconstruction of buildings in a block, or in the change of function of a neighbourhood. Such local changes, which may be considered bifurcations as they alter the structure and significance of a neighbourhood, may remain without any perceptible effect on the structure of the city as a whole. It is likely that it would take much longer for the whole structure of the city to be affected by the changes in the interactions among 
urban actors. The problem is therefore to find a proper adjustment between the temporal and spatial scales of the models and of their applications.

Wilson's model still supports the hypothesis that there are at least one or two situations where a city is in equilibrium. In the short-term, the commuting pattern satisfies the maximum entropy principle, whereas there may also be an equilibrium in the size and spatial distribution of shopping centers according to the preferences of consumers. Analytical solutions may be computed in both cases from the model and allow short-term predictions about the urban structure. On the contrary, P. Allen's model is not concerned with these short-term dynamics and consider only the longer term dynamics of the urban structures which are generated from an external demand by the economic, social and spatial interactions within the city. The right use of this model is in exploring the variety of the possible urban structures which may emerge over medium- or long-term periods from local changes, because of a massive investment in an infrastructure, for instance, or in a new shopping center, or in the value of some global parameter like transportation costs or conditions of living preferences of the households.

From these observations it is obvious that the performance of different models is very difficult to compare, even when they are formulated apparently in very similar ways (Lombardo et al., 1987). The integration of different speeds of evolution into the urban models, in connection with the spatial and time scales of impact and with the degree of reversibility of such changes, is still a major challenge for the modeling of urban structures. This means that better connections should be developed between urban modeling and urban analysis at lower scales of observation.

\section{Models of systems of cities}

Similar formulations have been developed for the simulation of the evolution of systems of towns and cities. Central place theory remains the major conceptual framework in this field. The dynamics aspects of this theory, although mentioned in early work (Christaller, 1933, p. 86-128), have received only discontinuous attention from urban theoricians, and are still not well formalised, despite a recent surge of interest in the question. $\mathrm{R}$. White uses difference equations, including spatial interaction, to describe (through costs equations) the relationships between retail activities and consumers. He links the more concentrated or more dispersed spatial pattern of centres mainly to the interaction parameter and tests the compatibility of the simulated urban hierarchy with a rank-size distribution for one-sector (White, 1977) and two-sector (White, 1978) simulations. The model however was not applied to observed systems. Allen and Sanglier (1979b) simulate the development of a system of central places. A system of differential equations is used for simulating the growth and differentiation process in a set of towns and cities in competition for 
the attraction and development of urban functions which may be allocated to certain locations either hierarchically or randomly. However, although they obtain final distributions of city size which satisfy the rank-size rule, the developments of the spatial patterns of centres over time are more typical of a market progressively colonised by entrepreneurs than a genesis of a realistic central place system, since the models starts with only two central locations, which share the whole region as their market areas (Allen, 1978).

Other insights in the dynamics of systems of cities have been gained by giving better specifications to the old "over-identified" model of the rank-size rule and by connecting it with dynamic processes. The statistical shape of the distribution of city sizes is not a sufficient description of the hierarchical structure of urban systems. A considerable improvement in measuring the degree of universality of Zipf's "law" is made if reliable and comparable informations are used for testing this simple model (Moriconi, 1993). The law has been demonstrated to be connected with an almost stochastic spatial distribution of urban growth (Gibrat, 1931, Pumain, 1982, Roehner and Wiese, 1982, Winiwarter, 1984). However, the pure random process has to be combined with the historical process of space-time contraction in order to become a proper description of the demographic evolution of an urban system (Pumain, 1982, Guérin-Pace, 1992). This has been related in a dynamic model to a competitive migration process, where the city size distribution can be conceived of as a stable attractor (Haag, 1994).

More recent work pays attention to the expression of spatial competition between cities. This field of research has long been neglected because of the relative lack of data about the flows of any kind, except population, between cities. Interesting empirical studies had demonstrated the strong interdependency of the towns and cities belonging to the same urban system, which are highly connected by information flows (Tornqvist, 1973). Studies had exemplified the propagation of short-term fluctuations (Marchand, 1981), as well as the similarities in medium-term socioeconomic transformations (Pumain, Saint-Julien, 1978) or the long-term diffusion of innovations (Pred, 1966 and 1973, Rozenblat, 1992) in systems of cities. The spatial representation and modeling of interurban connections are not easy. For instance Cauvin and Reymond (1980 and 1985), after Dacey (1974) have tried to model the spacing of cities, whereas Muller (1983) proposed to represent their differences in accessibility by using non-euclidean spaces. Fik and Mulligan (1990) modeled internodal flows within the traditional framework of central place theory, whereas Krmenec and Esparza (1993) developed a model of flows including exchanges of "spatial" goods (for which demand decreases with distance) as well as "non-spatial" goods (which can be exchanged between two centers of the same level). More research still has to be done in 
order to integrate the hierarchical concepts of central place theory and the specialisation process of cities into a dynamic theory of systems of cities.

The models available until now seem better adapted for simulating the competition between already established urban centres than for simulating the genesis and adaptation of a settlement system. On the other hand, one may wonder if the methods in use are well suited for dealing with the full complexity of urban systems. Modelling with differential equations has some advantages: the model is written fairly concisely and it can be tested under certain conditions with a guarantee of repeatability. However, such models treat geographical space as an isotropic function of distance, using various synthetic spatial interaction formulations. It is difficult for them to take into account a large variety in the range and scope of spatial interactions and also to consider more than two different geographical scales at the same time. More flexible simulation tools may give better results in this repect (see section 5).

\section{Analytical or micro-level approaches}

The Cartesian philosophy still has some adepts who do not hesitate to deal with urban complexity by developing analytic investigations. If urban macro-structures are thought of as products of interactions between actors at the microlevel, it is logical to start with a good understanding of the behaviour of those actors. Some authors like Boudon (1984) deny any usefulness and real theoretical value to models from the social sciences which do not give a meaningful interpretation from the point of view of the individual: "Methodological individualism" may be a basis for an analytical urban research. It can be illustrated by very theoretical or by empirical studies.

\subsection{The New Urban Economics}

Typical of this approach is the set of works gathered under the generic name of "New Urban Economics. They apply in a systematic way the concepts and methods of micro-economics to the analysis of urban forms. William Alonso in his thesis "Location and land use" first published in the sixties may appear as the initiator of this field of research which has proliferated since then, essentially in the main journals of the Regional Science. Reviews about it were given for instance first by Richardson (1977) and later on by Fujita (1989).

The interesting contribution of these works is that they integrate the principles of economic theory with a strict definition of concepts and a rigorous use of mathematical tools. The formalism starts with hypotheses about individual behaviour and ends with deductions of urban spatial patterns at 
the macrolevel. The main issues considered are the spatial distribution of population and employment densities, the market valuation of accessibility inside cities, the effects of nuisances and urban amenities on the location of households, the search for agglomeration economies by firms, and the genesis of polycentric agglomerations through the appearance of secondary job centres in the periphery (Gannon, 1993).

Since the first applications of von Thünen's ideas about the game of bid-rents and the determining effect of the distance to the center in explaining most of the spatial pattern of urban land use and the location choices of households (arbitrating between the cost of land and transportation costs in Alonso's model), several improvements have been brought into the models in order to relax the over simplistic hypothesis of "homo economicus" behaviour. Various forms of individual utilities have been integrated in order to take into account the diversity of urban actors (White, 1988); the mechanisms of social spatial segregation have been considered (Rose-Ackerman, 1975); the competition between traffic and other types of land use has been investigated (Solow, 1972, Kanemoto, 1975); more complicated metrics have been proposed for the description of urban space (Huriot, Perreur, 1990); the effect of uncertainties and incomplete information on spatial forms have also been considered (Andrulis, 1982, Beaumont, 1990).

Two main difficulties are still preventing this highly theoretical approach from totally dominating urban research by its explanatory power and the precision of its analytical tools. The first, less applicable in English, American or Japanese cities, but highly relevant in other countries, concerns the respective role of market mechanisms and public decisions in the shaping of cities. Weighting the two types of effects within models still remains a delicate exercise. The second criticism is also linked with urban complexity. Despite vive uncertainties or imprecisions, the models of the New Urban Economics are still inspired by the ideas of relative optimisation in the determination of the urban spatial structure and of a trend towards an equilibrium in the explanation of urban change. In this respect, this approach is highly questionable for the theoreticians who hold cities to be evolutionary, complex systems.

\subsection{Individual behaviour in urban space}

Another direction of research follows the same theoretical line with different methods of investigation. It is related both to empirical surveys of the spatial behaviour of urban actors and to their modelling in the framework of discrete choice theory, resting upon the principles of random utility theory (Macmillan, 1993). 
Empirical research on spatial behaviour has shed new light on the underlying motivations and determinants of moves in urban space. Sample surveys are treated by using methods of categorical data analysis and of longitudinal data analysis. Reviews of that field of resarch are given by Timmermans and Borgers (1985), Wrigley and Longley (1984). The main applications have improved knowledge about residential mobility, identifying several types of residential strategies according to the characteristics and to the biography of the individuals, and completing previous investigations about the effects of the characteristics of the supply-side in the process of housing choice (Clark, Deurloo, Dieleman, 1984, van Wissen, Rima, 1988). The same type of approach has been applied to shopping trips: for instance, evaluating the relative importance of multipurpose trips in the shopping behaviour of consumers. $\mathrm{H}$. Timmermans (1980) contradicts one of the main hypotheses of central place theory -the assumption that the consumer chooses the closest place of supply for every level of services is demonstrated to be false. Consequences for the geometry of central places are derived, both inside cities and in regional networks of cities (Toninato, 1979). The rationales for the location of stores within cities have been investigated by the same type of survey and discrete choice modeling (Wrigley, 1988).

By trying to link in a very explicit manner the observations made about individuals and the aggregate structures, a method such as the micro-simulation seems promising for meeting one of the hardest challenges imposed by the complex character of urban systems, which is the integration of these levels holistic way. Urban research still has a great deal of work to accomplish before improved knowledge about the behaviour of individuals, their aspirations and mental representations can be successfully integrated into aggregate models of cities. Empirical investigations and specific surveys are too rare. They should be related in a systematic way to urban modeling in order to provide relevant variables and parameters for the description of urban evolution. This need for relevant descriptors has become even more urgent since very flexible and powerful tools have been developed and used for urban simulations, like cellular automata, multi-agent systems, or fractal models.

\section{Simulating the relation between micro behaviour and macro structures}

The growing demand for models which generate various urban spatial forms has encouraged the development of a class of methods which derive city maps from hypotheses made about the behaviour of urban actors under specific assumptions or constraints. Contrasting with the models quoted above (section 4), these do not try to make exact predictions but are mainly exploratory. They are mainly simulation models, not making any hypotheses about the optimisation of a given constraint, nor supposing any trend towards equilibria. 
This field of research also has a long history since $T$. Hägerstrand in the fifties was perhaps the first to develop simulation of spatial patterns over a grid representing a geographical space and the evolution of a spatial pattern over time according to precise hypotheses about imitation behaviour leading to spatial diffusion effects. The uncertainty about the exact location of potential imitators was simulated by a Monte Carlo method, introducing stochasticity into a process guided by the spatial distribution of information around each decisor (mean information field). The method was used to reproduce the spatial extension of black ghettos in some North-American cities (Morrill, 1965a) and for a theoretical simulation of the development of an urban system under a spatial process of migrations of population (Morrill, 1965b).

Various types of application have improved those first ideas and methodologies for developing simulation models of urban spatial patterns.

\section{1 Urban micro-simulation}

Social and spatial macro-structures may be considered the product of interactions among individuals, each of them following a life-time trajectory, with probability constraints on the transitions from one individual state to another, through household, professional or migratory "events". This idea has been applied to the reconstruction of global social or spatial structures from very large samples of simulated life stories (Holm, Oberg, 1984, 1989). Despite the large number of individual (about 100,000 ), and despite giving a reasonable result at the aggregate level of the whole of Swedish society, the method still does not allow us to generate spatial patterns which are detailed enough for a transposition to the simulation of urban space.

Researchers at Leeds (Clarke, 1990), use an inverse approach to derive representative individual profiles from an urban information available at the level of urban blocks. The probabilities of occurence of a set of characteristics are computed from census block records, and sets of fictitious individuals are generated from a random game simulating them. This method allow further studies of the interactions between individual characteristics (for instance, unemployment and nationality). It also makes it possible to integrate various levels of analysis and to make predictions about needs in transportation means or services. However, the method is rather heavy to handle for a large number of city blocks and it is difficult to generalize the observations to other cities.

At much more detailed scales of observations and extending Hägerstrands' ideas about a "time geography", (1970), Janelle, Goodchild and Klinkenberg (1988) and Goodchild, Klinkenberg and Janelle (1993) discuss the question of spatial and temporal aggregation of data describing the everyday space-time behaviour of individuals within a city. More investigations in other urban contexts would 
need to be made before the results can be generalized. Microanalytic urban modeling techniques will probably improve by integrating geographic information systems and microsimulation models (Wegener, 1986).

\subsection{Cellular automata}

A cellular automaton consists of an array of cells which may be in any one of several qualitative states. At each iteration, the state of each cell may remain the same or change to another state according to the state of the neighbouring cells. Some models like the famous "game of life", although very simple (cells have only two possible states, alive or dead) may give rise to a full variety of spatial configurations. More complex cellular automata are useful in urban research if they allow for several possible states and sophisticated definitions of the neighbourhood. W. Tobler (1979) first mentioned cellular automata as the "geographical type" of models. H. Couclelis drew attention to their use for modeling micro-macro relationships in spatial dynamic models (1985) and for deriving complex dynamics from simple rules (1988). R. White (1991) applied this formalism to simulate the evolution of land use patterns within urban areas, according to a table of probability of change from one type of use to the other. White and Engelen (1993) checked the fractality of the resulting simulated urban spatial structures. Portugali and Benenson (1994) applied the method for generating spatial distributions of communities inside a city according to their preferences for a type of social neighbourhood. A model of spatial urban growth using a two-state cellular automata process for the filling of built-up space in periurban fringes as well as in an entire urban area in the long term has been developed by Batty and Xie (1994). This last paper, instead of exploring only the theoretical possibilities of the model, also tries to calibrate it with an observed urban evolution.

\subsection{Multi-agent systems}

The methodology of multi-agent systems is a part of Distributed Artificial Intelligence. These systems are conceived as societies of autonomous agents who are able to act on themselves and on their environment. The agents can communicate with other agents and their behaviour is the result of their observations, their knowledge and their interactions with other agents. The determinants of an agent's behaviour have a local character, there is no global constraint on the system's dynamics. The general behaviour of the system is produced by the combination of actions of the agents. Such multi-agent systems can in some way be considered as experimental devices materializing the hypotheses of selforganisation theory.

One could imagine several applications of multi-agent systems in the urban realm, simulating for instance interactions between urban actors, applying principles of game theory or replicating an 
urbanistic game like SIMCITY. However, the first application of this methodology has been given for another level of organisation of the urban systems. The method has been transposed in order to simulate the emergence of a system of towns and cities from a rural settlement system, over a long time period. Through a competition process for accumulating the surplus of agriculture in their vicinity, drawing benefits from long distance trade and developing new sources of profit from innovations, some settlements become towns and cities. Each settlement can be considered an "agent", whose "behaviour" is defined by the properties of the aggregate entity that it represents. Their interactions and transformations, which are simulated by the multi-agent system, produce a system of cities whose structure and evolution can be compared with empirical evolution of historical urban systems. The SIMPOP model is able to simulate several types of settlement systems, with more or less specialised and hierarchised patterns (Bura et al., 1993).

The multi-agent system method of modeling has the same ability as cellular automata to simulate a large variety of spatial configurations. Compared to classical cellular automata, it also allows a greater variety of spatial interaction, including variable extension of spatial range of the interactions, which can be defined by connexity on a network as well as by contiguity, according to the characteristics of each agent. Moreover, instead of allowing only a few possible qualitative states for each cell, the method is able to integrate any qualitative or quantitative description of an agent, whose behaviour may be very complicated. Compared to the simulations by sets of differential equations, the method is very flexible. It allows for a much more detailed representation of spatial interactions and of some local properties and also makes it possible to introduce new agents or new rules into the model without changing the other parts of it. The risk in applications could be a loss in generality of the model, since the rules may easily be adapted to specific or local cases. It is also not easy to express them in the usual mathematical formulations, since quantitative and qualitative rules are mixed in the model.

As in the case of cellular automata, and more generally with all simulation models, the use of this method is more deductive than experimental. Well-known rules can be introduced and parameters evaluated at the level of individual agents in order to reproduce some observed behaviour at the global level of the system. However, it cannot be inferred from a satisfying correspondence between simulation and reality that this set of rules is the only one leading to such a result. The validation of the model remains a difficult problem.

\subsection{Fractals}

The conception of urban entities as fractal objects is another way of connecting them to the field of study of complex systems. Evidence of the fractality of urban forms has been given by several authors, either by looking at cities boundaries, or by exploring the relationship between the area and 
perimeter of cities, or by computing fractal dimensions for the built-up areas of cities (Batty, Longley, 1994, Frankhauser, 1994). The same authors have also used simulation models for reproducing fractal structures in a process of urban growth. Batty and Longley mainly used a "diffusion limited aggregation" approach, whereas Frankhauser was able to connect several more concrete rules of urban growth into a simulation model of fractal growth. Connection between buildings and networks development, inclusion of old villages in an expanding urban area, and the preservation of green spaces around already built-up structures were the main processes leading to fractal urban forms. Other investigations have been made about the fractal character of a hierarchy of central places (Arlinghaus, 1990, Frankhauser, 1994), but they remain for the moment theoretical.

The application of fractal ideas to urban structures is not only a matter of improving the morphological description of cities. It also may be useful in changing the references which are normally used for understanding their genesis. For instance, the concept of density for urban residential population or land use is not perhaps relevant to a real understanding of an urban aggregate of population and buildings, whereas the concept of fractality (or density gradient) could more easily be related to a theory of urbanity. The same transposition may also be fruitful when interpreting the hierachical structure of systems of cities directly, in the framework of a fractal process of occupation of space, instead of considering it as the anormal product of some "externalities" (Pumain, 1995)

\section{The question of chaos}

In discussing the dynamics of complex systems, the question of chaos must be included. It seems however to be generally formulated at too abstract levels to be of relevance for urban research. It is true that some of the mathematical models which are in use for simulating urban evolutions, as migration models, or models of change in land use, as well as May's famous logistic equation, may exhibit chaotic behaviour. But, in all such cases, it appears that the range of parameters which can give rise to chaos never belong to the realm of variation of those parameters in the real world. May's equation starts being chaotic for growth rates of more than two hundred per cent per unit of time. The migration model derived from a master equation approach would exhibit chaotic behaviour if the same migratory preferences were maintained for a thousand years (Haag, 1994), the cellular automata simulating changes in land use would give chaotic results if a store changed its activity twice in the same day (White, 1983)! Shall we think more in philosophical terms about the consequences of such highly hypothetical possibilities when applying those models to real urban objects, or can we neglect this behaviour as going beyond the normal range of observations? After all, a regression line is a mathematical model with two infinite ends, but this vertiginous possibility never prevented anybody from making restricted use of the portion of the model necessary to adjust to real data! Instead of asking "is our world chaotic?" perhaps the 
reverse question would be more interesting: "why is our urban world not chaotic?" What are the social regulations which prevent the rise of chaotic behaviour of our urban systems and ensure relative stability to the trajectories of the objects that we are studying? 


\section{Conclusion}

There is an obvious distance between the theoretical features mentioned in section 1 which lead us to think about urban areas as complex systems, and the results which are now available from the applications of complex system theory to urban research. Either we have made wrong hypothesis about the nature of urban complexity, or the actual state of urban research is too little advanced to solve the main theoretical difficulties.

What are the reasons for such a relative failure? A few hypotheses can be made. First, the fascination of pure mathematics is undeniable. The beauty of a cusp catastrophe curve, the attractiveness of trajectories spiralling towards a sink and the appealing aesthetics of strange attractors are more seductive than the ordinary poorly fitted discontinuous curves of empirical observations. One also must admit that the mathematics of complexity are difficult to understand and to explain, and that a first introduction to this domain could not easily manage both initiation to that theory and its experimentation on the urban realm. Another possible explanation lies in the unease aroused by the apparent lack of control from the user upon the results of the models. The normal outputs are only exploratory, they show a few possibilities among those which could happen in reality. The model demand a real effort of confidence from the decision-makers: first they have to believe in the specification of the model, and this is more difficult to make firm with simulation models than with calculation ones, according to the difficulties of calibration when bifurcations are possible; second, it is very difficult for actors to admit that their action may not very often be decisive, and that it may end as a fluctuation of little importance in the more general urban dynamics where it is embedded.

So it is perhaps not surprising that the modelling of urban complexity has not received until now much returns back from interactions with urban planners. It is more worrying that theoricians have not been concerned enough by the necessary links between new theoretical appoaches and empirical evidence for the development of a comprehensive theory of urban change. Despite this gap in theoretical research, the present partial review shows that a number of new possibilities are now available for exploring the dynamics of urban structures. Perhaps the main challenge in urban research is now in developing better connections between the mathematical and computational tools and their applications to observed urban evolution and planning operations. The question of the transfer of the concepts should be investigated more deeply than it has been done until now. 


\section{References}

Alonso W., 1964, Location and Land Use. Cambridge, Mass., Harvard University Press.

Allen, P.: 1978, 'Dynamique des centres urbains', Sciences et Techniques 50, 15-19.

Allen P. Boon F. Deneubourg J.L. de Palma A. Sanglier M. 1981, Models of Urban Settlement and Structure as Dynamic Self-organizing Systems. Washington, DC, US Department of Transportation.

Allen, P. and M. Sanglier: 1978, 'Dynamic models of urban growth', Journal of Social and Biological Structures 1, 265-280.

Allen, P. and M. Sanglier: 1979a, 'Dynamic models of urban growth', Journal of Social and Biological Structures 2, 269-298.

Allen, P. and M. Sanglier: 1979b, 'A dynamic model of growth in a central place system', Geographical Analysis 11, 256-272.

Allen, P. and M. Sanglier: 1981, 'Urban evolution, self organisation and decision-making', Environment and Planning 13, 168-183.

Allen, P., G. Engelen and M. Sanglier: 1984a, 'Computer handled efficiency stimuli exploration' Final Report, Noord Holland, Contract for Provinciaal Bureau Energiebesparing.

Allen, P., G. Engelen and M. Sanglier: 1984b, 'Self-organizing systems and the laws of socio-economic geography', Brussels working papers on spatial analysis, serie A, $n^{\circ} 4$.

Amson, J.C.: 1975, 'Catastrophe theory: a contribution to the study of urban systems', Environment and Planning 2, 175-221.

Anas A. 1984, Discrete choice theory and the general equilibrium of employment, housing, and travel networks in a Lowry-type model of urban economy. Environment and Planning A, 16, 1489-1502.

Andrulis J. 1982, intra-urban workplace and residential mobility under uncertainty. Journal of Urban Economics, 11, 1, 85-97.

Arlinghaus S.L. 1985, Fractals take a central place, Geografiska Annaler, 83-88.

Arlinghaus S.L. 1989, The fractal theory of central place geometry, Geographical Analysis, 21, 2, 104-121.

Aydalot P. 1985, Economie régionale et urbaine. Paris, Economica.

Bairoch P. 1985, De Jericho à Mexico, ville et économie dans l'histoire. Paris, Gallimard.

Batten D. 1992, Network cities, infrastructure and variable return to scale, Congress of the Regional Science Association, Palma de Mallorca.

Batty, M.: 1976, Urban Modelling, Cambridge, Cambridge University Press.

Batty, M.: 1992, Urban Modelling in Computer-Graphic and Geographic Information Systems Environments. Environment and Planning $B, 19,663-688$.

Batty, M.: 1993, Cities and complexity: the implications for modeling sustainability. Paper presented at the 4th International Workshop on Technological change and Urban Form, Berkeley, 14-16 April. 
Batty, M. and Karmeshu: 1983, 'A strategy for generating and testing models of migration and urban growth' Regional Studies 17, 223-236.

Batty M. Longley P. 1994, Fractal cities, a geometry of form and function. London and San Diego, Academic Press.

Batty M. Xie Y. 1994, From cells to cities. Environment and Planning B, 21, 31-48.

Beaumont C. 1990, Contribution à l'analyse des espaces urbains multicentriques. Dijon, Thèse de doctorat.

Beaumont, J.R., M. Clarke and A.G. Wilson: 1981a, 'The dynamics of urban spatial structure: some exploratory results using difference equations and bifurcation theory', Environment and Planning A13, 1473-1483.

Beaumont, J.R., M. Clarke and A.G. Wilson: 1981b, 'Changing energy parameters and the evolution of urban spatial structure', Regional Science and Urban Economics 11, 287-315.

Bennett, R.J., R.P. Haining and A.G. Wilson: 1985, 'Spatial structure, spatial interaction and their integration: a review of alternative models', Environment and Planning A19, 625-645.

Berry B.J.L. 1964, Cities as systems within systems of cities. Papers of the Regional Science Association, 13, 147-163.

Berry B. Pred A. 1961, Central Place Studies. Philadelphie, Regional Science Institute.

Bertuglia C. S. La Bella A. eds, 1991, I sistemi urbani. Milano, Franco Angeli, 2 vol.

Bertuglia, C.S., S. Ocelli, G. Rabino and R. Tadei: 1980, 'A model of urban structure and development of Turin: theoretical aspects', Sistemi Urbani, 2-3, 59-90.

Bertuglia, C.S., S. Ocelli, G. Rabino, C. Salomone and R. Tadei: 1983, 'The dynamics of Turin metropolitan area: a model for the analysis of the processes and for the policy evaluation', Paper presented at the 23rd Congress of the Regional Science Association, Poitiers.

Bertuglia C.S., Leonardi G., Occelli S., Rabino G.A., Tadei R. and Wilson A.G. 1987, Urban Systems: Contemporary Approaches to Modelling. London, Croom Helm.

Bertuglia C.S., Leonardi G., Wilson A.G. (eds) 1990, Urban Dynamics, Designing an integrated model. London, Routledge.

Bertuglia C.S. Clarke G.P. Wilson A.G. (eds) 1994, Modelling the City: Performance, Policy and Planning. London, Routledge.

Bird J. 1977, Centrality and cities, London, Routledge and Kegan Paul.

Birkin M. Clarke G.P. Clarke M. Wilson A.G. 1990, Elements of a model-based geographic information system for the evaluation of urban policy, in Worrall L. (ed.) Geographical Information Systems: developments and applications, London, Belhaven Press, 133-162.

Botero G. 1588, Della Ragion di Stato: delle cause della grandezza delle città. Torino, Luigi Firpo.

Boudon R. 1984, La place du désordre. Critique des théories du changement social. Paris, P.U.F.

Bourne L.S. 1993, The demise of gentrification: a commentary and prospective view. Urban Geography, 14, 1, 95-107.

Bura S. Guérin-Pace F. Mathian H. Pumain D. Sanders L. 1996, Multi-agents systems and the dynamics of settlement systems. Geographical Analysis., 4 .. 
Bussière, R. and T. Stovall: 1981, Systèmes évolutifs urbains et régionaux à l'état d'équilibre, Paris C.R.U.

Camagni R. 1990, Strutture urbane gerarchiche e reticolari: verso una teorizzazione, in Curti F. Diappi L. eds, gerarchie e reti di città: tendenze e politiche, Milan, Franco Angeli.

Camagni, 1992, Economia urbana. Milano, Franco Angeli.

Camagni R. 1993, Organisation économique et réseaux de villes, in Sallez A. ed., Les villes, lieux d'Europe, Paris, Editions de l'Aube, 107-128.

Camagni R. Diappi L. Leonardi G. 1986, Urban Growth and Decline in Hierarchical systems: a supply-oriented dynamic approach. Regional Science and Urban Economics, 16, 145-160.

Casti, J. and H. Swain: 1975, Catastrophe Theory and Urban Process, RM-75-14, I.I.A.S.A., Laxenburg.

Casetti E. 1991, Testing Catastrophe Hypotheses. Socio-spatial dynamics, 2, 2, 65-80.

Cauvin C. Reymond H. 1980, Cartographie informatisée et géographie humaine. CNRS, ATP expérimentations en cartographie transformationnelle, t.2, $150 \mathrm{p}$.

Cauvin C. Reymond H. 1985, L'espacement des villes, Paris, CNRS, Mémoires et Documents de Géographie.

Cauvin C. Reymond H. Schaub R. 1989, Accessibilité, temps de séjour et hiérarchie urbaine. Sistemi Urbani, 3, 297-324.

Chevalier M. 1832, Exposition du système de la Méditerranée, Le Globe, 12 juillet.

Christaller W.: 1933, Die Zentralen Orte in Süddentschland, Iena, Fischer.

Clark W.A.V. 1985, Residential segregation in American cities, University of California at Los Angeles.

Clark W.A.V. Deurloo M.C. Dieleman F.M. 1984, Housing consumption and Residential Mobility, Annals of the Association of American Geographers, 74, 29-43.

Clarke M. 1990, Regional Science in industry and commerce: from consultancy to technology transfer. Environment and Planning B, 17, 257-268.

Clarke M. and Wilson A.G. 1987, Towards an applicable human geography. Environment and Planning A, 19, 1525-1541.

Clarke, M. and A.G. Wilson: 1983a, 'The dynamics or urban spatial structure: progress and problems', Journal of Regional Science 23, 1-18.

Clarke, M. and A.G. Wilson: 1983b, 'Exploring the dynamics of urban housing structures: a 56 parameter residential location and housing model', Paper presented at the 23rd Congress of the Regional Science Association, Poitiers.

Claval P. 1981, La logique des villes. Paris, LITEC.

Couclelis H. 1988, Of mice and men: what rodent population can tell us about complex spatial dynamics. Environment and Planning A, 20, 99-109.

Couclelis, H.: 1985, 'Cellular worlds: a framework for modeling micro-macro dynamics', Environment and Planning A17, 585-596.

Dacey M.F. 1974, One dimensional Central Place Theory, Northwestern University, Studies in Geography $\mathrm{n}^{\circ} 21$. 
DATAR, 1991, En Europe, des villes en réseau. Paris, La Documentation française.

Dematteis G. 1985, Verso strutture urbane reticolari, in Bianchi G. Magnani I. eds, Sviluppo regionale: teorie, metodi, problemi, Milan, Franco Angeli.

Dematteis G. 1990, Modelli urbani a rete, in Curti F. Diappi L. (a cura di), Gerarchie e reti di città: tendenze e politiche, Milano, Franco Angeli.

Dendrinos, D.S.: 1980, 'A basic model of urban dynamics expressed as a set of Volterra-Lotka equation's in Catastrophe Theory in Urban and Transport Analysis, Washington D.C., Department of Transportation.

Dendrinos, D.S.: 1984, 'The structural stability of the US regions: evidence and theoretical underpinnings' Environment and Planning A16, 1433-1443.

Dendrinos, D.S. and G. Haag: 1984, 'Toward a stochastic dynamical theory of location: empirical evidence' Geographical Analysis 16, 287-300.

Dendrinos, D.S. and H. Mullaly: 1981, 'Evolutionary patterns of urban populations' Geographical Analysis 13, 328-344.

Dendrinos D.S. Mullaly H. 1985, Urban Evolution: Studies in the Mathematical Ecology of Cities. Oxford, Oxford University Press.

Diappi L. Ottana M. 1994, City network system: the neuronal approach. Milano, Politecnico, unpublished paper.

Domanski, R. and A.P. Wierzbicki: 1983, 'Self organisation in dynamic settlement systems', Papers and Proceedings of the Regional Science Association 51, 141-160.

Duby G. (ed) 1980 , Histoire de la France urbaine. Paris, Seuil, vol. 1.

Dupuy G. ed. 1988, Réseaux territoriaux, Caen, Paradigme et CNRS, groupe Réseau.

Emanuel C. Dematteis G. 1990, Reti urbane minori e deconcentrazione metropolitana nella Padania centrooccidentale, in Martellato D. Sforzi F. eds, Studi sui sistemi urbani, Milan, Franco Angeli.

Ernst, I.: 1978, 'Formalisation du processus d'urbanisation: une application de la théorie des catastrophes' Cahiers de la SEMA 2, 75-90.

Fletscher R. 1986, Settlement in Archaeology: world-wide comparison. World Archaeology, 18, 1, 59-83.

Fik T.J. Mulligan G.F. 1990, Spatial Flows and Competing Central Places: Towards a General Theory of Hierarchical Interaction. Environment and Planning A, 22, 527-549.

Fischer M. 1993, New Developments in Mathematical modeling. Budapest, 8th Colloquium on Theoretical and Quantitative Geography.

Forrester, J.W.: 1969, Urban Dynamics, Cambridge (Mass.) M.I.T. Press.

Fournier R. 1990, Le modèle CARPE. Université de Paris X Nanterre, thèse de 3e cycle en économie.

Frankhauser P. 1994, La fractalité des structures urbaines. Paris, Anthropos.

Fujita M. 1989, Urban Economic Theory, Land use and City size. Cambridge University Press.

Gannon F. 1993, Modèles de la Ville et Politiques Urbaines Optimales. Université de Paris X-Nanterre, Thèse de doctorat. 
Goodchild M.F. Klinkenberg B. Janelle D.G. 1993, A Factorial Model of Aggregate Spatio-Temporal Behaviour: Application to the Diurnal Cycle. Geographical Analysis, 4, 277-294.

Griffith, D.A. and A.C. Lea (eds): 1984, Evolving Geographical Structures, Nato Advanced Institute Series, Martinus Nijhoff, Den Haag.

Griffith, D.A. and R. Mack Kinnon (eds): 1981, Dynamic Spatial Models, Sijthoff and Nordhoff, Alphen aan den Rijn, Netherlands.

Guérin-Pace F. 1992, Deux siècles de croissance urbaine. Paris, Anthropos.

Haag, G.: 1984, A dynamic model for the migration of human populations, in Griffith D.A. and Lea A.C.: Evolving Geographical Structures, Nato Advanced Institute Series, Martinus Nijhoff, Den Haag, 24-61.

Haag G. 1994, The rank-size Distribution of Settlements as a Dynamic Multifractal Phenomenon. Chaos, solitons and Fractals, 4, 4, 519-534.

Haag, G. and D.S. Dendrinos: 1983, 'Toward a stochastic dynamical theory of location: a non linear migration process', Geographical Analysis 15, 269-286.

Haag, G. and W. Weidlich: 1984, 'A stochastic theory of interregional migration', Geographical Analysis 16, 331-357.

Haag G. Munz M. Pumain D. Sanders L. Saint-Julien T. 1992, Interurban Migration and the Dynamics of a System of Cities. Environment and Planning A, 24, 181-198.

Haag G. 1994, The rank-size distribution of settlements as a dynamic multifractal phenomenon. Chaos, Solitons and Fractals, 4, 4, 519-534.

Hägerstrand T. 1970, What abour people in regional science? Papers of the Regional Science Association, 24, 7-21.

Haken, H.: 1977, Synergetics, an Introduction. Berlin, Springer, 2nd ed.

Harris B. Wilson A.G. 1978, Equilibrium values and dynamics of attractiveness terms in productionconstrained spatial interaction models. Environment and Planning A, 10, 371-88.

Holm E. Oberg S. 1984, Migration in micro and macro perspectives. Scandinavian Population Studies, 1, 6184.

Huberman B.A. (ed) 1988, The Ecology of Computation, North-Holland, Elsevier.

Huriot J.M. Perreur J. 1990, Distances, Métriques et Représentations de l'espace. Revue d'Economie Régionale et Urbaine, 2, 197-237.

Kanemoto Y. 1975, Congestion and cost-benefit analysis in cities. Journal of Urban Economics, 2, 246-264.

Kauffman S. 1993, The origins of order. New York, Oxford University Press.

Isard, W. and P. Liossatos: 1979, Spatial Dynamics and Optimal Space-Time Development, North-Holland, New-York.

Janelle D.J. Goodchild M.F. Klinkenberg 1988, Space-time diaries and Travel characteristics for Different levels of Respondent Aggregation. Environment and Planning A, 20, 891-906.

Juillard E. 1972, Espace et temps dans l'évolution des cadres régionaux, in Etudes de géographie tropicale offertes à P. Gourou, Paris, Mouton, 29-43. 
King L. 1962, A quantitative expression of the pattern of urban settlements in selected areas of the United States. Tidjschrift voor Economische en Sociale Geographie, 53, 1-7.

Krmenec A.J. Esparza A. 1993, Modeling Interaction in a System of Markets. Geographical Analysis, 4, 354368.

Le Maître A. 1682, La Métropolitée ou de l'établissement des capitales, de leur utilité passive et active, de l'union de leurs parties, de leur anatomie, de leur commerce. Amsterdam, B. Boekholt.

Lepetit B. 1984, Chemins de terre et voies d'eau. Réseaux de transport et organisation de l'espace en France (1740-1840). Paris.

Lepetit B. Pumain D. (eds) 1993, Temporalités urbaines. Paris, Anthropos.

Lombardo S. Pumain D. Rabino G. Saint-Julien T. Sanders L. 1987, Comparing Urban Dynamic Models: the unexpected differences in two similar models. Sistemi Urbani, 2.

Lombardo, S. and G. Rabino: 1983, 'Non linear dynamic experiment', Paper presented at the 23rd European Congress of the Regional Sciences Association, Poitiers.

Lung, Y.: 1985, 'A la recherche de nouvelles techniques ou d'un nouveau paradigme : à propos d'approches récentes de l'espace économique, Cahiers d'Econométrie Appliquée, 1, 69-77.

Macmillan W.D. 1993, Urban and Regional modelling: getting it done and doing it right. Environment and Planning A, Anniversary Issue, 56-68.

Marchand C. 1981, Maximum entropy spectra and the spatial and temporal dimensions of economic fluctuations, Geographical Analysis, 95-116.

Martin J.P. 1988, L'analyse des réseaux en géographie, études de cas, in Dupuy G. ed., Réseaux territoriaux, Caen, Paradigme et Groupe Réseau, 229-250.

May, R.M.: 1976, 'Simple Mathematical Models with very Complicated dynamics', Nature, 261, 459-467.

Mees, A.I.: 1975, The revival of cities in medieval Europe. An application of catastrophe theory', Regional Science and Urban Economics 5, 403-425.

Mills E.S. McKinnon J. 1973, Notes on the New Urban Economics, Bell Journal of Economics and Management Science, 4, 593-601.

Mikula B. Mathian H. Pumain D. Sanders L. 1994, Dynamic modelling and Geographical Information System: for an integration, in Longley P. Batty M. (eds), Spatial Analysis and GIS, London, Routledge.

Moriconi-Ebrard 1993, L'urbanisation du monde depuis 1950. Paris, Anthropos.

Morrill R.L. 1965a, Migration and the spread and growth of urban settlement. Lund Studies in Geography, Serie B, 26.

Morrill R.L., 1965b, The Negro Ghetto: problems and alternatives. Geographical Review, 339-361.

Muller J.C. 1983, La cartographie des espaces fonctionnels, L'Espace Géographique, 2, 142-152.

Mulligan G.F. 1984, Agglomeration and central place theory: A review of the litterature. International Regional Science Review, 9, 1-42.

Murayama Y. 1982, Canadian urban system and its evolution process in terms of air-passenger flows, Geographical Review of Japan, 55-6, 380-402. 
Nystuen J.D. Dacey M. 1961, A graph theory interpratation of nodal regions, Papers of the Regional Science Association, 29-42.

Paelinck, J.: 1980, 'Dynamic urban growth models', Papers of the Regional Science Association 24, 25-37.

Papageorgiou, G.J.: 1980, 'On Sudden urban growth', Environment and Planning A, 12, 1035-1050.

Peschel, M. and W Mende: 1983, Leben wir in einer Volterra Welt ?, Akademie Verlag, Berlin.

Portugali J. Benenson I. Omer I. 1994, Socio-spatial residential dynamics: stability and instability with a selforganizing city. Geographical Analysis, 4, 321-340.

Pred A. 1966, The spatial dynamics of US industrial growth 1800-1914. Cambridge, MIT Press.

Pred A. 1973, Systems of cities and information flows, Lund Studies in Geography, Serie B, 38.

Pred A. 1977, City systems in advanced societies. London, Hutchison.

Pred, A.: 1984, 'Place as historically contingent process: structuration and the time-geography of becoming places', Annals of the Assocation of American Geographers 74, 279-297.

Prigogine, I. and I Stengers: 1979, La Nouvelle Alliance, Paris, Gallimard.

Pumain, D.: 1982, La Dynamique des Villes, Economica, Paris.

Pumain D. 1984, L'évolution séculaire de la trame urbaine, in Quant T. Géoscopie de la France, Paris, Minard, 153-174.

Pumain D. 1989, Spatial Dynamics and Urban Models, in Hauer J. Timmermans H. Wrigley N. ed, Urban Dynamics and Spatial Choice Behaviour, Dordrecht, Kluwer, 155-174.

Pumain D. 1991, City size dynamics in urban systems. Cambridge, Department of Archaeology, Symposium on Dynamic modeling and human systems.

Pumain D. 1992, Les systèmes de villes, in Bailly A. Pumain D. Ferras R. Encyclopédie de Géographie, Paris, Economica.

Pumain D. 1993, L'espace, le temps et la matérialité des villes, In Lepetit B. Pumain D. (eds), Temporalités urbaines, Paris, Anthropos, 135-157.

Pumain D. 1995, Pour une théorie évolutive des villes.

Pumain D. Saint-Julien T. 1978, Les dimensions du changement urbain. Paris, CNRS.

Pumain, D., L. Sanders and T. Saint-Julien: 1989, Villes et auto-organisation, Paris, Economica.

Pumain, D., T. Saint-Julien and L. Sanders: 1984, Dynamics of spatial structure in French urban agglomerations, Papers of the Regional Science Association, vol. 55, 71-82.

Pumain, D., T. Saint-Julien and L. Sanders: 1986, Urban dynamics of some French cities, European Journal of Operational Research 25, 3-10.

Pumain, D. Robic M.C. 1994, Théoriser la ville. Communication au colloque de Saint-Dié, Penser la ville, ASRDLF.

Puu, T.: 1981, 'Catastrophic structural changes in a continuous regional model', Regional Science and Urban Economics 11, 317-333. 
Rabino G. 1993, The Evolution Theory and urban modeling. Budapest, 8th Colloquium in Theoretical and Quantitative Geography.

Racine J.B. 1993, La ville entre Dieu et les hommes. Genève, Presses bibliques et universitaires et Paris, Anthropos.

Reclus E. 1895, The Evolution of cities. The Contemporary Review, 67, 2, 246-264.

Reymond, H.: 1981a, 'L'ouverture informatique en géographie urbaine: de l'analyse multivariée socioéconommique à la simulation organique des systèmes urbains', Informatique et Sciences Humaines 50, 9-20.

Reymond, H.: 1981b, 'Une problématique théorique de la géographie: plaidoyer pour une chorotaxie expérimentale', in Isnard H., Racine J., Reymond H. (ed.) Problématiques de la Géographie, P.U.F., Paris.

Reynaud, J.: 1841, 'Villes', in Encyclopedie Nouvelle, cité par M.C. Robic, 'Cent ans avant Christaller, une théorie des lieux centraux,' l'Espace Géographique, 1982.

Richardson H.W. 1977, The New Urban Economics, an alternative. A.J. Scott.

Robic M.C. 1982, Cent ans avant Christaller, une théorie des lieux centraux. L'Espace Géographique.

Roehner, B. and K. Wiese: 1982, 'A dynamic generalization of Zipf's rank-size rule', Environment and Planning A14, 1449-1467.

Roehner, B.: 1983, 'Contribution à l'étude des processus stochastiques de naissance et mort: aspects théoriques et application', Université Paris IV, thèse de doctorat d'Etat.

Rose-Ackerman S. 1975, Racism and urban structure. Journal of Urban Economics, 2, 85-103.

Rosser J.B. 1991, From Catastrophe to Chaos: a general Theory of Economic Discontinuities. Boston, Kluwer.

Rozenblat C. 1992, Le réseau des entreprises multinationales dans le réseau des villes européennes. Université Paris I, thèse de doctorat.

Sanders L. 1992, Système de villes et synergétique. Paris, Anthropos.

Sanders L. Pumain D. 1992, La formalisation du changement dans trois modèles de dynamique urbaine: une étude comparative. Revue d'Economie Régionale et Urbaine, 5, 773-794.

Sheppard, E.: 1985, 'Urban system population dynamics: incorporating non linearities', Geographical Analysis $17,47-73$

Solow R.M. 1972, Congestion, Density and the use of land in transport. Swedish Journal of Economics, 1, 161173.

Sonis M. 1985, Hierarchical structure and central-place system, the barycentric calculus and decomposition principle. Sistemi Urbani, 3-28.

Taaffe E. Morrill R. Gould P. 1963, Transport extension in underdeveloped countries, Geographical Review, 4, 503-529.

Thom, R.: 1974, Modèles Mathématiques de la Morphogénèse, Christian Bourgeois, Paris

Timmermans H. 1980, Central Place Theories and Spatial Shopping Behaviour. University of Nijmegen, $\mathrm{PhD}$ thesis. 
Timmermans H. Borgers A. 1985, Spatial choice models: fundamentals, trends and prospects. Eindhoven, University of Technology.

Tobler W. 1979, Cellular Geography, in Gale S. Olsson G. eds, Philosophy of Geography, Dordrecht, Reidel.

Toninato G. 1979, Une nouvelle approche de la théorie des places centrales, le concept de centralité imparfaite. Strasbourg, thèse de $3 \mathrm{e}$ cycle.

Tornqvist G.E. 1973, Systems of Cities and Information Flows, Lund Studies in Geography, Serie B, 38.

Vauban, 1707, Projet d'une dîme royale, publié par Pirou S., Simiand F., (dir.), 1933, Paris, Félix Alcan, coll. des principaux économistes.

Vlora N.R. 1979, Città e territorio. Bologne, Pàtron.

Wagstaff, J.M.: 1977, 'A possible interpretation of settlement pattern development in terms of "catastrophe theory"', Transaction, Institute of British Geographers 3, 165-178.

Wegener, M.: 1983, 'A simulation study of movement in the Dortmund housing market', Tijdschrift voor Economische en Sociale Geografie 74, 267-281.

Wegener, M. 1986, Integrated forecasting models of urban and regional systems. London Papers in Regional Science, 15, 9-24.

Wegener M. 1994, Operational Urban Models, State of the Art. Journal of the American Planning Association, 60,1 , Winter.

Weidlich W. Haag G. 1982, Concepts and Models of a Quantitative Sociology. Heidelberg, Springer Series in synergetics.

Wheatley, 1971, The pivot of the four quarters. Edinburgh, University Press.

White M. 1988, Location choice and commuting behaviour in cities with decentralized employment. Journal of Urban Economics, 129-152.

White, R.W.: 1977, 'Dynamical central place theory', Geographical Analysis 9, 226-243.

White, R.W.: 1978, 'The simulation of central place dynamics: two sector systems and the rank size rule', Geographical Analysis 10, 201-208.

White, R.W.: 1983, 'Chaotic behaviour and the self-organization of urban retail systems', Brussels working papers on spatial analysis, serie $A, n^{\circ} 3$.

White R. 1989, The artificial intelligence of urban dynamics: neural network modelling of urban structure. Papers of the Regional Science Association, 67, 43-53.

White R. 1991, A cellular automata approach to the evolution of urban land use patterns. Stockholm, 7th colloquium of Theoretical and Quantitative Geography.

White R. Engelen G. 1993, Fractal urban land use patterns. A cellular automata approach to the evolution of urban land use patterns. Environment and Planning A, 25.

Whitehand J.W.R. 1987, The changing face of cities. Oxford, Blackwell.

Wilson, A.G.: 1981, Catastrophe Theory and Bifurcation: Application to Urban and Regional System, Croom Helm, London. 
Wilson, A.G.: 1984, 'Making urban models more realistic: some strategies for future research', Environment and Planning 16, 1419-1432.

Winiwarter, P.: 1984, 'Iso-dynamics of population-size distribution in hierarchical systems', Paper presented at the annual meeting of the Society for General Systems Research, Los Angeles.

van Wissen L. Rima A. 1988, Modelling Urban Housing Market Dynamics. Amsterdam, North Holland.

Wrigley N. 1988, Store Choice, Store Location and Market Analysis. London, Routledge.

Wrigley N. Longley P.A. 1984, Discrete Choice Modeling in Urban Analysis, in Herbert D.T., Johnson R.J. (eds), Geography and the Urban Environment, Chichester, J. Wiley, 45-94.

Zhang W.B. 1990, Stability versus instability in urban pattern formation. Socio-spatial dynamics, 1, 41-56. 